\title{
Research on the Application of Traditional Cultural Elements in Modern Art Design
}

\author{
Yaoyao Zhang ${ }^{1, \text { a * }}$ \\ ${ }^{1}$ Yinxing Hospitality Management College of Chengdu University of Information and \\ Technology,Chengdu city Sichuan Province,610000 \\ aya21yo@126.com
}

Yaoyao Zhang, born in February 2nd of 1984, Han nationality, comes from Chengdu of Sichuan Province, acquire the degree of Master, now serving as a lecturer at Yinxing Hospitality Management College of Chengdu University of Information and Technology, the research direction of her is environmental art design at Yinxing Hospitality Management College of Chengdu University of Information and Technology

Keywords: Traditional culture; Modern art; Chinese culture; Design

\begin{abstract}
The civilization of China has a long history of more than 5000 years. Through the ages, it has vicissitudes and accumulations of culture much more than any other countries in the world. The 5000 years of history leaves us not only the old days to be remembered, but also the accumulation of culture and changes and upgrade of tradition. There is no doubt that in the worldly cultural garden, Chinese culture occupies a large land. Some people even say that the most beautiful cultural elements exist in China. However, the splendid elements and cultural deposits have not been explored in the modern time and some part of traditional culture has not been endowed with new concepts that comfort to the new age. Therefore, traditional culture might be ill-adapted to modern people. Culture is objective originally and it has no responsibility. As descendants of Chinese civilization, we should fully uphold the Chinese excellent traditional culture and make a lift of it so as to make it possess new vitality and energy in the new age. In nowadays society, in the area of designing, inspiration is the core essential factor though it comes with certain contingency. Chinese traditional cultural elements are an important origin of inspiration and they have been applied into their designs in recent years. This paper attempts to discuss the successful cases of how Chinese traditional cultural elements are used in modern art design and points out some mistakes and misunderstandings about the integration of traditional culture and modern art design.

China is a large country with huge territory and a large number of population and it is a country with diverse nationalities. From the longitudinal aspect, it has a long history of 5000 years, experiencing numerous times of changes and transformations, thus it has accumulated profound cultural deposits; while from the horizontal aspect, it has large territorial areas with many nationalities and different regions and areas represent different cultural customs which all together make up of the Chinese culture we see now. Seen from whatever aspect, Chinese culture possesses a huge market potential that remains to be explored. Traditional cultural element is an abstract concept which includes many things. It is the conclusion and summary of China's 5000 years of culture and the condense of excellent traditions. It includes the objective existing substance and subjective ideology that has injected into the body of Chinese people. To be specific, it refers to the specific substances such as cheongsam, panda, four treasures of the study, the four great inventions, calligraphy, couplet, Chinese painting, shadow play, opera, seal cutting, verses and songs, kites, porcelain, the five elements and eight diagrams, Chinese knot, tai chi, paper-cut art, Dunhuang mural and facial make-up in opera and so on; while in the area of ideology, it has much more flourishing ideas such as "the theory that man is an integral part of nature", harmony is precious, of all virtues piety is most important and the great harmony, etc. What we have mentioned here are a small part of Chinese culture, so it can be figured out that traditional cultural elements are fruitful and they can input bountiful sources of inspiration for modern design art.
\end{abstract}




\section{Analysis on the application of traditional cultural elements in modern art design}

\section{The application of traditional cultural elements in filmography and animation}

With China's rapid development and growth, its international status has been promoted steadily which also represents that Chinese culture wins a place and the frequency of its occurrence in the international world is much higher than before. The reasons that Chinese culture has a more important status in international society are Chinese people's praise and propaganda of it and western developed countries' intention to cater to Chinese people's tastes in order to open Chinese market, thus many western art products have integrated with traditional Chinese cultural elements. Whether actively or passively, we have a direct impression of the application of traditional cultural elements in TV productions and animation culture and many of them have won a great success. For an instance, the China-made animated film Big Fish and Begonia coming out in 2015 has been prepared for 12 years and this movie is depicted based on China's ink and wash painting. Therefore, every scene of this movie places the audience in the picture of traditional Chinese painting, and the realistic scenes and profound artistic conception make people pleased and fascinated. At the same time, the animated film shows us Chinese cultural substances such as "the legendary fish" and couplets, and the style of buildings and costumes of characters are integrated into the movie perfectly. Most importantly, at the first of movie, it quotes Wandering in Absolute Freedom of Zhuangzi, the ancient Chinese philosopher and elaborates the core of the movie. Although there is polarization of the movie's criticisms, it can not be denied that it is a successful attempt to mix traditional cultural elements with modern art design.

Director Zhang Yimou demonstrates the fantastic and charming Chinese kung fu and calligraphy for the audiences in his movie Hero. Also, the fascinating locations of the movie and the scene of Jack Li and Tony Leung Chiu Wai's duel on the surface of a lake which presents the effect of landscape painting surprise the audience to a great extent. What's more, Zhang's use of colors is unable to be caught up with. Hero's main colors are blue, white and green, and the colors diverse as the unfolding of the movie. For example, in the wild field, Tony Leung Chiu Wai wears in green which blends with the water and mountains. It gives beautiful visional experience and demonstrates the concept of "man is an integral part of nature" and most importantly shows the state of mind by using green.

\section{The application of traditional cultural elements in designing logos}

Beijing Olympic Games has past for about 10 years, and every time we talk about it, we Chinese would have the feeling of proud and pleasant. The design of many logos and buildings are good topic for people all over the world to talk about, not to mention the great achievement and tremendous impact to the world. Talking about Beijing Olympics' logo, we have to mention the emblem of it which is "Imprint of China, Dancing Beijing". The emblem is designed based on Chinese seal and it integrates China's traditional cultural elements with the Olympic spirit which is a demonstration of the charm of Chinese culture. Also, the character "Jing" refers to Beijing which means the Olympic Games is host in Beijing. The character looks like a person doing sport which symbolizes active and industrious Chinese people. It is amazing that a simple emblem shows so many cultural elements at one time.

It is a must to mention China Unicom when talking about the design of a company's logo. The logo of China Unicom is designed referring to traditional Chinese knot, integrating Chinese red into its design. It not only uses the elements of traditional cultural elements but also indicates the hope and vision of the company. Red is the most widely used color in China and it represents harmony and well-off of people's life, therefore, China Unicom uses red as its main color shows the beautifulness of Chinese culture and the aspiration of development. In addition, Chinese knot is a Chinese element, and it is complex and intricate but every part is independent which shows fluent and open of network communication. The further meaning of the logo is that China Unicom's network is fluent, the company is the long lasting. This logo is a symbolic case of the combination of Chinese elements and modern art design and the brilliance and talent of designer amaze people. 


\section{Analysis on mistakes and misunderstandings about the integration of traditional culture and modern art design}

\section{Modern art design should not ignore the excellent traditional elements}

Chinese civilization is brilliant and profound, going through ups and downs during the past 5000 years but still standing in the world. There is no other country or nation in the world can compete with us. The reason for this phenomenon is the cultural deposits of China that cannot be reached by any other countries and as a Chinese we should have an awareness of this deeply. However, modern China is detached from the world because of subjective reasons which leads to a humiliating history. The history make many Chinese have a wrong feeling that Chinese culture is far left behind the western one. What's more, the western world has gone through twice industrial revolution, thus they are in the lead in many fields. Therefore, many people begin to chase after western culture and ideology but forget the cultural heritage our ancestors left us. This representation of this idea in modern art design is that artists and designers ignore our cultural elements, hold the opinion that traditional Chinese elements occupy no market and are not attractive. Rather, they think we should follow the values praised by the western world, and only in this way can people's need satisfied. This idea is definitely wrong. In recent years, there are numerous successful cases of the combination of traditional cultural elements and modern art, and it is conceit to detach the world.

The integration of modern art design and traditional cultural elements should focus on both forms and connotations

It is undeniable that with China's economic growth and upgrade of its international status, China and western developed countries begin to apply China's traditional cultural elements into their art design which represent the trend of fashion, show the benefit of stimulating Chinese people's resonance and open Chinese market. For instance, Hollywood's animated movie Mulan and Kung $\mathrm{Fu}$ Panda have acquired very high public praise and good box office. Thus, modern art designers start to apply Chinese cultural elements in their works and this trend benefits us and this influence not only propagandize Chinese culture, but also make Chinese people realize the specificity and greatness of their culture and stimulate the sense of national pride. However, many designers just use these elements in the surface but do not understand or demonstrate the significance and connotation behind, thus, they cannot realize the effect of their initial imagination.

\section{References}

[1] Sun Zhiyu. Analysis on the originality of Chinese traditional cultural elements by analyzing Kung Fu Panda. 2010(01).

[2] Li Jingxin. Research on the impression and integration of "Chinese elements" in modern art design[J], Art and Design Theory, 2014 (07) : 26-28.

[3] Chen Xiangzhen. The application of China's traditional cultural art elements in modern design [J].Tradition and Innovation, 2010(5). 